Supporting Information for:

\title{
Polyurethane Ionophore-Based Thin Layer Membranes for Voltammetric Ion Activity Sensing
}

Maria Cuartero, Gaston A. Crespo* and Eric Bakker*

Department of Inorganic and Analytical Chemistry, University of Geneva, Quai Ernest-Ansermet 30, CH1211 Geneva, Switzerland.

Corresponding Author: eric.bakker@unige.ch; gaston.crespo@unige.ch 


\section{Experimental Section}

Reagents, Materials and Instruments. Poly(methylmethacrylate-decylmethacrylate) (MMA-DMA) copolymer was prepared as previously described ${ }^{1}$ using the following chemicals: monomers methylmethacrylate (99\%) and n-decyl methacrylate (99\%), the initiator 2,2'-azobis(2methylpropionitrile) (98\%), ethyl acetate (reagent grade) and 1,4- dioxane (reagent grade) supplied by Sigma-Aldrich.

Multi-walled carbon nanotubes (MWCNTs, $>95 \%$ wt. purity, outer diameters of 10-20 nm, length $\sim 50$ $\mu \mathrm{m})$ purchased from HeJi, Inc. (Zengcheng City, China), octadecylamine (ODA), cross-linker 1,6hexanediol diacrylate, photoinitiator 2,2-dimethoxy-2-phenylacetophenone and n-butyl acrylate monomer (all reagents in analytical and selectophore grades) purchased from Fluka (Buchs, Switzerland) were used to synthesise lipophilic multi-walled carbon nanotubes (f-MWCNTs) as previously described. ${ }^{2}$

GC-electrode tips (6.1204.300) with an electrode diameter of $3.00 \pm 0.05 \mathrm{~mm}$ were sourced from Metrohm (Switzerland). A rotating disk electrode (Autolab RDE, Metrohm Autolab B.V., Utrecht, The Netherlands) was used to spin coat the membranes on the electrodes at $1500 \mathrm{rpm}$.

For impedance experiments a PGSTAT 302N combined with a FRA32M module was used. Ellipsometric experiments were made using an ellipsometer (Multiskop, Optrel) with a $632.8 \mathrm{~nm}$ Laser. Potentiometric measurements were taken against the double-junction $\mathrm{Ag} / \mathrm{AgCl} / 3 \mathrm{M} \mathrm{KCl} / 1 \mathrm{M} \mathrm{LiOAc}$ reference electrode, using a 16-channel EMF interface (Lawson Laboratories, Inc., Malvern, PA).

Surface images were taken using a JSM-6510LV low vacuum scanning electron microscope (SEM) (JEOL Ltd., Tokyo, Japan).

Ellipsometric experiments were made using an ellipsometer (Multiskop, Optrel) with a $632.8 \mathrm{~nm}$ Laser. A volume of $30 \mu \mathrm{L}$ of the corresponding membrane cocktail was deposited by drop casting (1500 rpm) on glassy carbon plates (Sigradur G, $2.5 \times 2.5 \times 1.1 \mathrm{~cm}$ ) purchased from HTW (Germany). The ellipsometric parameters $(\Delta$ and $\Psi)$ were recorded as a function of the angle of incidence from $60^{\circ}$ to $75^{\circ}$ at every $0.5^{\circ}$ for bare plate as well as different deposited membranes. The software Matlab_R2012b was used for the simulations to obtain first the refractive index of the GC plates and then the thicknesses of the different membranes.

Preparation of the electrodes. Poly(3-octylthiophene) (POT) was electropolymerized on GC surface by cyclic voltammetry (two scans, $0-1.5 \mathrm{~V}, 100 \mathrm{mV} \mathrm{s}^{-1}$ ) and then discharged at $0 \mathrm{~V}$ for $120 \mathrm{~s}$. A solution containing $0.1 \mathrm{M}$ of OT and $0.1 \mathrm{M} \mathrm{LiClO}_{4}$ in acetonitrile purged with $\mathrm{N}_{2}$ for 30 min was used. After electropolymerization, the electrode was immersed in pure acetonitrile for $30 \mathrm{~min}$, to remove the electrolyte, and dried at room temperature for $15 \mathrm{~min}$. Thereafter, a volume of $25 \mu \mathrm{L}$ of the corresponding 
cocktail was spun coated on the POT-based electrode. Table 1 shows the composition of the membrane cocktails used through the paper.

For potentiometry, all-solid-state electrodes based on f-MWCNTs were prepared according to Yuan et $a l^{3}$ A total volume of $100 \mu \mathrm{L}$ of a f-MWCNTs solution in THF $\left(1 \mathrm{mg} \mathrm{mL}^{-1}\right)$ was deposited by drop casting on the GC electrode (10 $\mu \mathrm{L}$ x 10 times, waiting until THF evaporation before each deposition). Six membrane cocktails were prepared: i) $48 \%$ of PU, $48 \%$ of DOS and $40 \mathrm{mmol} \mathrm{kg}^{-1}$ of NaTFPB in 1 $\mathrm{mL}$ of THF, ii) $48 \%$ of PU, $48 \%$ of DOS, $40 \mathrm{mmol} \mathrm{kg}^{-1}$ of NaTFPB and $80 \mathrm{mmol} \mathrm{kg}^{-1}$ of Li-I in $1 \mathrm{~mL}$ of THF; iii) $48 \%$ of PU, $48 \%$ of DOS, $40 \mathrm{mmol} \mathrm{kg}$ of NaTFPB and $80 \mathrm{mmol} \mathrm{kg}-1$ of K-I in $1 \mathrm{~mL}$ of THF; iv) $32 \%$ of PVC, $64 \%$ of DOS and $40 \mathrm{mmol} \mathrm{kg}^{-1}$ of NaTFPB in $1 \mathrm{~mL}$ of THF; v) $32 \%$ of PVC, $64 \%$ of DOS, $40 \mathrm{mmol} \mathrm{kg}^{-1}$ of NaTFPB and $80 \mathrm{mmol} \mathrm{kg}{ }^{-1}$ of Li-I in $1 \mathrm{~mL}$ of THF; vi) $32 \%$ of PVC, $64 \%$ of DOS, $40 \mathrm{mmol} \mathrm{kg}{ }^{-1}$ of NaTFPB and $80 \mathrm{mmol} \mathrm{kg}^{-1}$ of K-I in $1 \mathrm{~mL}$ of THF. A total volume of $250 \mu \mathrm{L}$ of the corresponding cocktail was drop casted on the f-WCNT film $(50 \mu \mathrm{L}$ x 5 times, waiting until THF evaporation before each deposition). The electrodes were conditioned for 12 hours in $1 \mathrm{mM}$ chloride solution of the corresponding discriminate cation $(\mathrm{NaCl}, \mathrm{KCl}$ and $\mathrm{LiCl}$ for blank potassium and lithium membranes respectively).

Ellipsometry. The thickness of the different polymeric membranes (I-IV, Table 1) was measured by using ellipsometry. First, the simulation of the angular dependence of the ellipsometric parameters ( $\Delta$ and $\Psi)$ for the GC plates (free of membrane) allowed the complex refractive index $\left(N_{s}=n_{s}-k_{s} i\right)$ of the bare surface to be determined. The obtained value $\left(N_{s}=1.9161-0.7251 i\right)$ was in agreement with those previously reported in literature. ${ }^{4}$ This value was used for the calculation of the membrane thicknesses at different incidence points. Figure SI-5 illustrates a representative fitting carried out for each membrane. The calculated average thickness for each polymer $(227 \pm 16 \mathrm{~nm}, 233 \pm 13 \mathrm{~nm}, 246 \pm 17 \mathrm{~nm}$ and $247 \pm 8 \mathrm{~nm}$ for PVC, PU, PS and MMA-DMA respectively) showed slight differences. However, the nature of the polymer matrix did not substantially influence on the thickness (few hundreds of nanometers) of the utilized membranes.

Electrochemical Impedance Spectroscopy. Electrical resistances of membranes I-IV were obtained by electrochemical impedance spectroscopy (EIS). Figure SI-6 displays the complex plots (-Z' vs. Z') for each polymer. Individual membranes behaved similar to a modified-Randles circuit with a characteristic semicircle at high-intermediate frequencies followed by Warburg diffusion element at low frequencies. Bulk resistances were therefore estimated from each semi-circle $(11.1 \pm 0.8 \mathrm{k} \Omega, 85.3 \pm 1.5 \mathrm{k} \Omega, 163.7 \pm 6.8$ $\mathrm{k} \Omega$ and 238.3 $\pm 7.6 \mathrm{k} \Omega$ for PVC, PU, PS and ACR). Calculated values increase in this order: $\mathrm{PVC}<\mathrm{PU}<$ PS $<$ MMA-DMA, indicating that PVC membrane presents the highest ionic conductivity and possibly the largest diffusion coefficient ${ }^{5}$ followed by PU membranes. 


\section{Tables}

Table SI-1. Composition of membrane cocktails.

\begin{tabular}{|c|c|c|c|c|c|c|c|c|}
\hline \multirow[t]{2}{*}{ Membrane } & \multirow[b]{2}{*}{$\mathrm{PVC}^{\mathrm{a}}$} & \multirow[b]{2}{*}{$\mathrm{PU}^{\mathrm{a}}$} & \multirow[b]{2}{*}{$\mathrm{PS}^{\mathrm{a}}$} & \multirow[b]{2}{*}{ MMA-DMA $^{\mathrm{a}}$} & \multicolumn{4}{|c|}{ Components } \\
\hline & & & & & $\mathrm{DOS}^{\mathrm{a}}$ & NaTFPB $^{b}$ & $\mathrm{Li}-\mathrm{I}^{\mathrm{b}}$ & $\mathrm{K}-\mathrm{I}^{\mathrm{b}}$ \\
\hline $\mathrm{I}^{\mathrm{c}}$ & 30 & & & & $60(2)$ & 40 & & \\
\hline II $^{\mathrm{d}}$ & & 49 & & & 49 (1) & 16 & & \\
\hline III $^{\mathrm{d}}$ & & & 49 & & $49(1)$ & 16 & & \\
\hline $\mathrm{IV}^{\mathrm{d}}$ & & & & 49 & $49(1)$ & 16 & & \\
\hline $\mathrm{V}^{\mathrm{d}}$ & & 40 & & & $60(1.5)$ & 16 & & \\
\hline VId & & 30 & & & $60(2.0)$ & 16 & & \\
\hline $\mathrm{VII}^{\mathrm{d}}$ & & 60 & & & $40(0.7)$ & 16 & & \\
\hline VIII $^{\mathrm{d}}$ & & 60 & & & $30(0.5)$ & 16 & & \\
\hline$I X^{d}$ & & 94 & & & $0(0)$ & 38 & & \\
\hline$X^{d}$ & & 49 & & & $49(1)$ & 20 & 40 & \\
\hline$X I^{d}$ & & 49 & & & $49(1)$ & 20 & & 40 \\
\hline $\mathrm{XII}^{\mathrm{c}}$ & 30 & & & & $60(2)$ & 68 & 40 & 40 \\
\hline XIII ${ }^{\mathrm{d}}$ & & 42 & & & $42(1)$ & 68 & 40 & 40 \\
\hline $\mathrm{XIV}^{\mathrm{d}}$ & & 44 & & & $44(1)$ & 40 & 40 & 40 \\
\hline$X V^{d}$ & & 42 & & & $42(1)$ & 75 & 40 & 40 \\
\hline
\end{tabular}


Table SI-2. Analytical parameters obtained for membranes i-vi interrogated by potentiometry.

\begin{tabular}{|c|c|c|c|c|c|}
\hline \multirow[b]{2}{*}{ Membrane } & \multirow[b]{2}{*}{ Cation } & \multicolumn{2}{|c|}{$\overline{P V C}$} & \multicolumn{2}{|c|}{$\mathbf{P U}$} \\
\hline & & 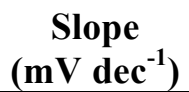 & LD (M) & $\begin{array}{c}\text { Slope } \\
\left(\mathrm{mV} \operatorname{dec}^{-1}\right)\end{array}$ & LD (M) \\
\hline \multirow[t]{3}{*}{ Blank } & $\overline{\mathrm{Li}}$ & $57.9 \pm 0.5$ & $(3.1 \pm 1.8) \times 10^{-5}$ & $55.3 \pm 0.6$ & $(5.1 \pm 1.4) \times 10^{-5}$ \\
\hline & $\mathrm{Na}$ & $58.4 \pm 0.4$ & $(7.9 \pm 1.9) \times 10^{-6}$ & $56.3 \pm 0.4$ & $(3.0 \pm 1.5) \times 10^{-5}$ \\
\hline & $\mathrm{K}$ & $58.5 \pm 0.9$ & $(7.8 \pm 1.0) \times 10^{-5}$ & $58.6 \pm 0.1$ & $(3.2 \pm 0.7) \times 10^{-5}$ \\
\hline \multirow[t]{3}{*}{ Li-I } & $\mathrm{Li}$ & $56.8 \pm 0.2$ & $(1.0 \pm 0.3) \times 10^{-6}$ & $58.4 \pm 0.1$ & $(2.2 \pm 0.8) \times 10^{-5}$ \\
\hline & $\mathrm{Na}$ & $32.8 \pm 0.8$ & $(4.3 \pm 1.5) \times 10^{-5}$ & $50.6 \pm 0.4$ & $(8.5 \pm 0.3) \times 10^{-5}$ \\
\hline & K & $40.6 \pm 0.8$ & $(4.7 \pm 1.1) \times 10^{-5}$ & $50.0 \pm 0.6$ & $(8.6 \pm 0.6) \times 10^{-5}$ \\
\hline \multirow[t]{3}{*}{ K-I } & $\mathrm{Li}$ & $2.3 \pm 1.1$ & $(2.0 \pm 2.1) \times 10^{-2}$ & $6.3 \pm 1.0$ & $(7.0 \pm 0.1) \times 10^{-3}$ \\
\hline & $\mathrm{Na}$ & $10.3 \pm 1.6$ & $(4.7 \pm 1.9) \times 10^{-3}$ & $10.2 \pm 1.5$ & $(1.9 \pm 0.1) \times 10^{-2}$ \\
\hline & $\mathrm{K}$ & $58.9 \pm 0.1$ & $(9.1 \pm 0.4) \times 10^{-7}$ & $58.9 \pm 0.3$ & $(8.5 \pm 0.7) \times 10^{-7}$ \\
\hline
\end{tabular}

Table SI-3. Calculated selectivity coefficients for membranes i-vi interrogated by potentiometry.

\begin{tabular}{ccccc}
\hline & & & \multicolumn{2}{c}{$\log K_{I, J}$} \\
Membrane & $\mathbf{I}$ & $\mathbf{J}$ & $\mathbf{P V C}$ & $\mathbf{P U}$ \\
\hline Blank & $\mathrm{Na}$ & $\mathrm{Li}$ & $-0.05 \pm 0.07$ & $1.21 \pm 0.02$ \\
& $\mathrm{Na}$ & $\mathrm{Na}$ & 0 & 0 \\
\multirow{4}{*}{ Lithium } & $\mathrm{Na}$ & $\mathrm{K}$ & $0.53 \pm 0.21$ & $-0.05 \pm 0.05$ \\
& $\mathrm{Li}$ & $\mathrm{Li}$ & 0 & 0 \\
& $\mathrm{Li}$ & $\mathrm{Na}$ & $-2.47 \pm 0.32$ & $-1.75 \pm 0.01$ \\
Potassium & $\mathrm{Li}$ & $\mathrm{K}$ & $-1.51 \pm 0.27$ & $-1.61 \pm 0.01$ \\
& $\mathrm{~K}$ & $\mathrm{Li}$ & $-6.23 \pm 0.25$ & $-5.03 \pm 0.30$ \\
& $\mathrm{~K}$ & $\mathrm{Na}$ & $-4.62 \pm 0.24$ & $-4.98 \pm 0.22$ \\
& $\mathrm{~K}$ & $\mathrm{~K}$ & 0 & 0 \\
\hline
\end{tabular}


Table SI-4. Determination of spiked lithium in undiluted serum and blood. $(n=3)$

\begin{tabular}{cccc}
\hline Biological Fluid & Added Li $\left(\mathrm{mmol} \mathrm{L}^{-1}\right)$ & Found $\left(\mathrm{mmol} \mathrm{L}^{-1}\right)$ & Recovery $(\%)$ \\
\hline Serum & 0.4 & $0.405 \pm 0.001$ & 101.3 \\
& 0.5 & $0.503 \pm 0.005$ & 100.6 \\
0.6 & $0.61 \pm 0.007$ & 101.7 \\
0.7 & $0.711 \pm 0.01$ & 101.6 \\
0.8 & $0.812 \pm 0.01$ & 101.5 \\
& 0.9 & $0.913 \pm 0.012$ & 101.4 \\
1 & $1.01 \pm 0.01$ & 101 \\
& 1.5 & $1.52 \pm 0.014$ & 101.3 \\
2 & $2.02 \pm 0.02$ & 101 \\
Blood & 2.5 & $0.53 \pm 0.02$ & 101.2 \\
& 0.4 & $0.501 \pm 0.002$ & 100.8 \\
& 0.5 & $0.612 \pm 0.005$ & 100.2 \\
& 0.6 & $0.712 \pm 0.01$ & 102 \\
& 0.7 & $0.81 \pm 0.01$ & 101.7 \\
& 0.8 & $0.915 \pm 0.015$ & 101.3 \\
& 0.9 & $1.02 \pm 0.015$ & 101.7 \\
& 1 & $1.513 \pm 0.01$ & 102 \\
& 1.5 & $2.03 \pm 0.01$ & 100.9 \\
2 & $2.57 \pm 0.01$ & 101.5 \\
& 2.5 & 102.8 \\
\hline
\end{tabular}




\section{Figures}

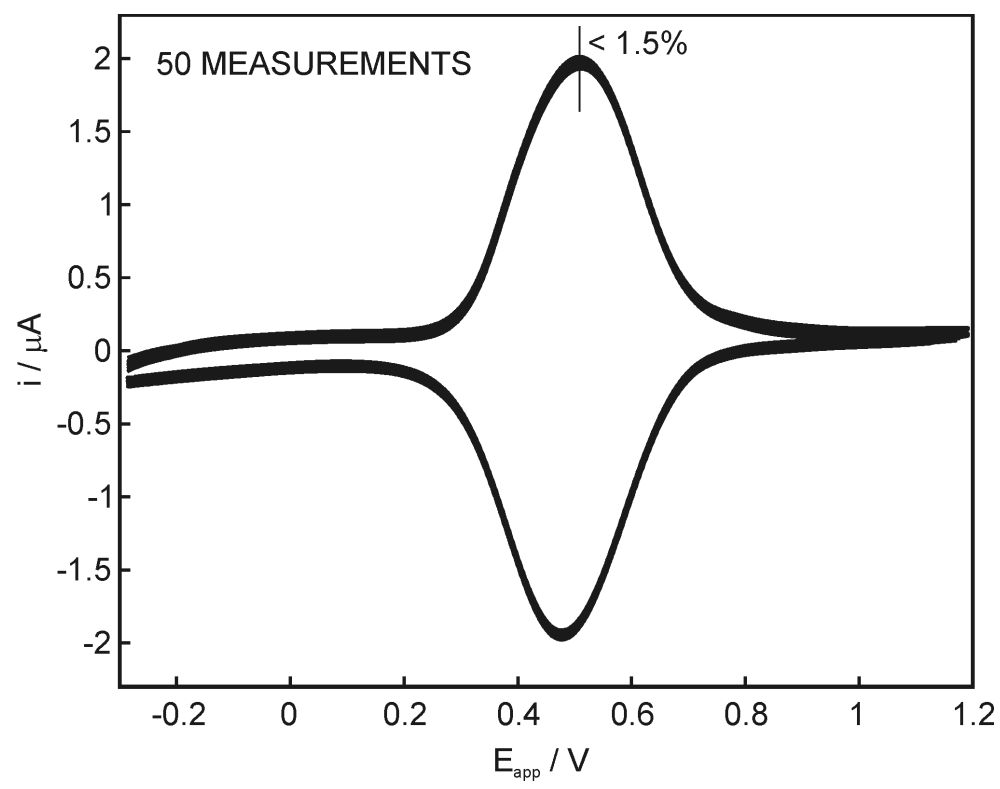

Figure SI-1. Cyclic voltammograms observed for PU membrane MII in $10 \mathrm{mM} \mathrm{NaCl}$ rinsing the membrane 50 times by a direct waterjet. 

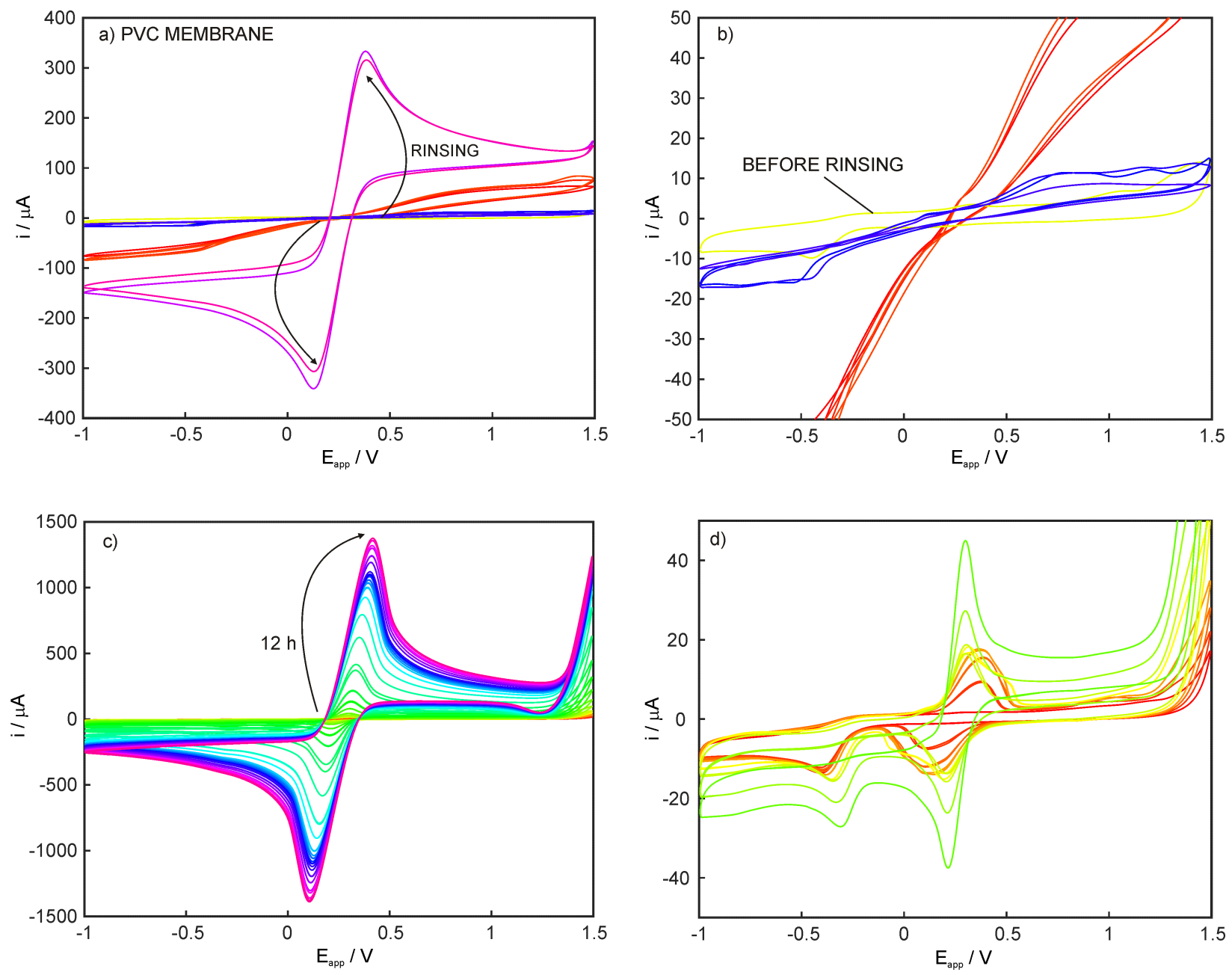

Figure SI-2. (a) Cyclic voltammograms obtained for thin PVC membrane (MI) in $0.1 \mathrm{M}\left[\mathrm{Fe}(\mathrm{CN})_{6}\right]^{3-}$ $/\left[\mathrm{Fe}(\mathrm{CN})_{6}\right]^{4-}$ after several heavy rinsing steps using a direct waterjet. (b) Zoom of the first curves. (c) Cyclic voltammograms obtained for thin PVC membrane in $0.1 \mathrm{M}\left[\mathrm{Fe}(\mathrm{CN})_{6}\right]^{3-} /\left[\mathrm{Fe}(\mathrm{CN})_{6}\right]^{4-}$ during a time period of $12 \mathrm{~h}$. (d) Zoom of the first curves. Background electrolyte: $0.1 \mathrm{M} \mathrm{NaCl}$. Scan rate: $100 \mathrm{mV} \mathrm{s}^{-1}$. 

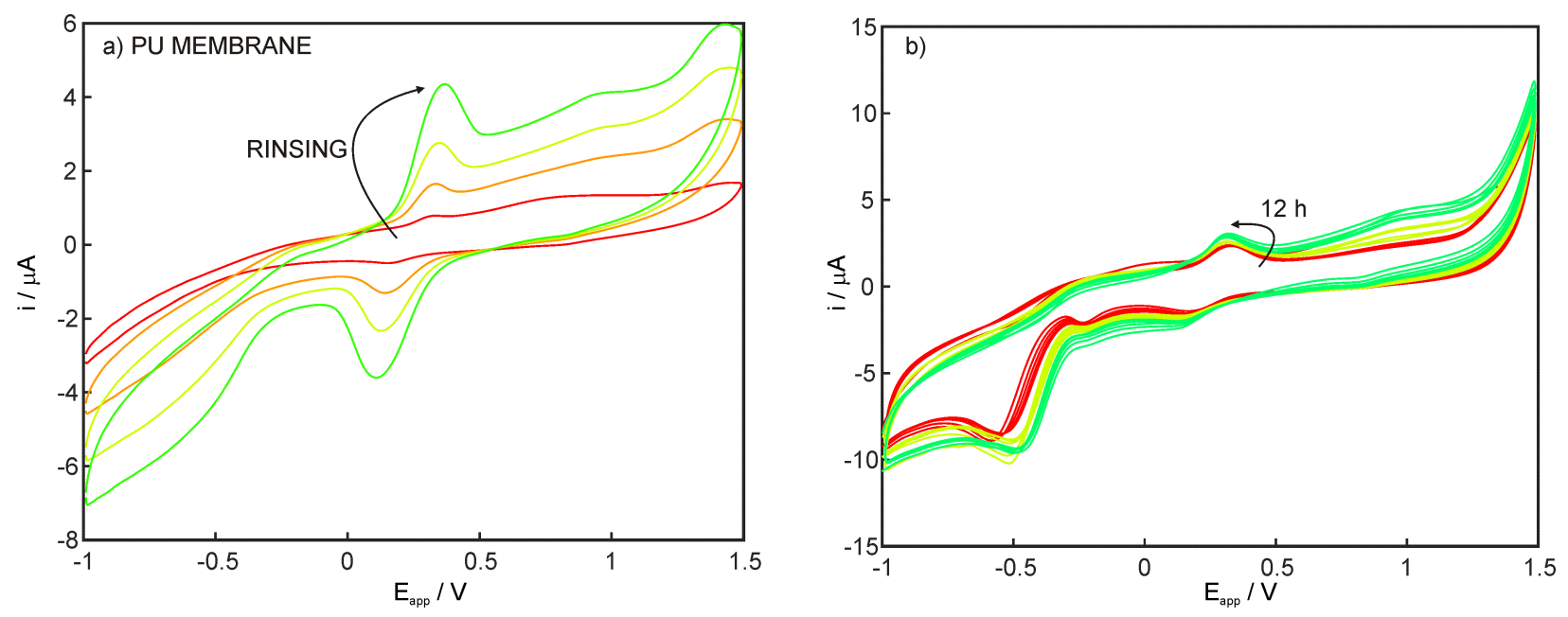

Figure SI-3. (a) Cyclic voltammograms obtained for thin PU membrane (MII) in $0.1 \mathrm{M}\left[\mathrm{Fe}(\mathrm{CN})_{6}\right]^{3-}$ $/\left[\mathrm{Fe}(\mathrm{CN})_{6}\right]^{4-}$ after several heavy rinsings using a direct waterjet. (b) Cyclic voltammograms obtained for thin PU membrane in $0.1 \mathrm{M}\left[\mathrm{Fe}(\mathrm{CN})_{6}\right]^{3-} /\left[\mathrm{Fe}(\mathrm{CN})_{6}\right]^{4-}$ during a time period of $12 \mathrm{~h}$ (45 min between each scan). Background electrolyte: $0.1 \mathrm{M} \mathrm{NaCl}$. Scan rate: $100 \mathrm{mV} \mathrm{s}^{-1}$. 

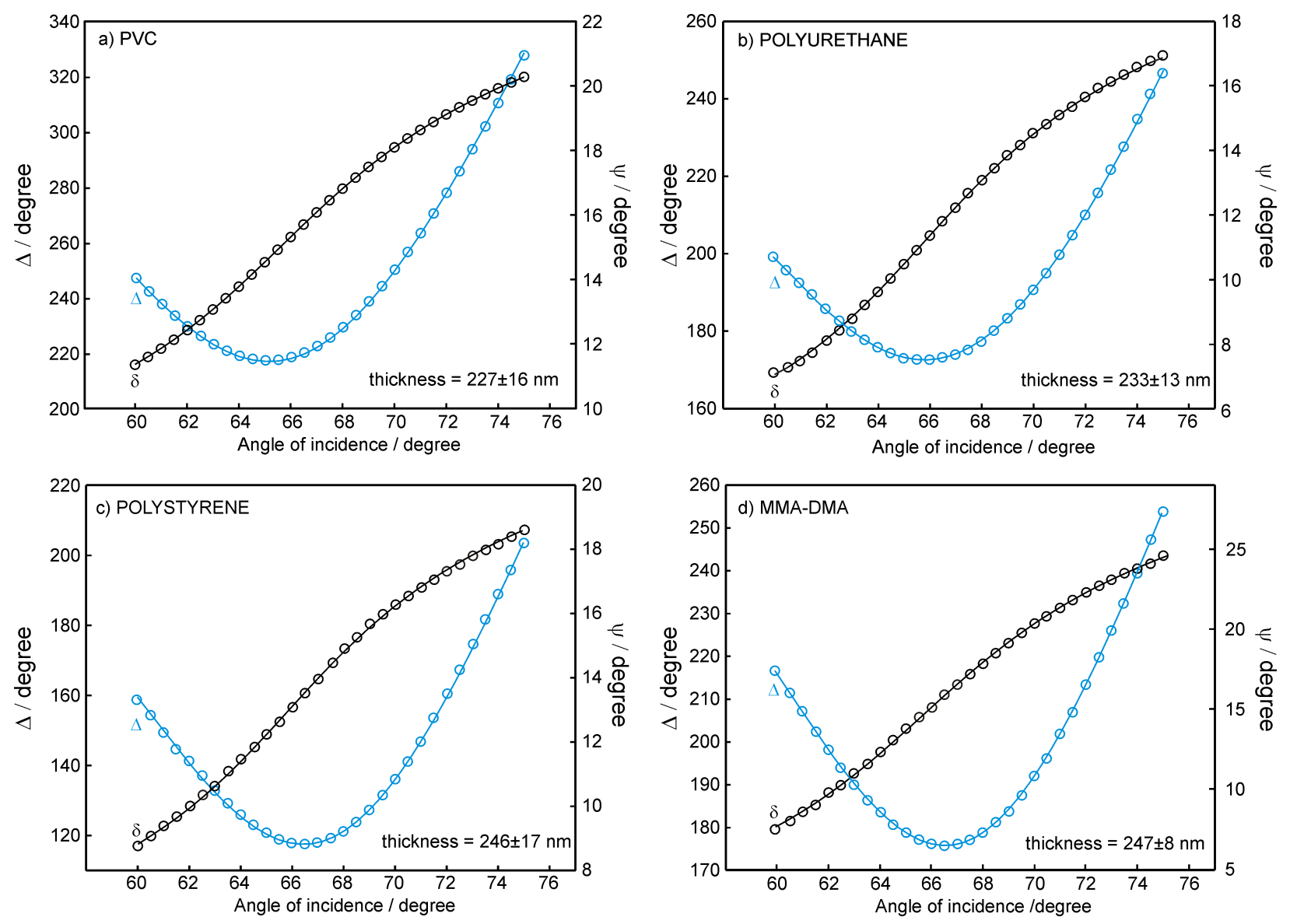

Figure SI-4. Ellipsometric characterization of a) PVC, b) polyurethane, c) polystyrene and d) MMADMA membranes (MI-IV, see Table SI-1). Ellipsometric parameters $\Delta$ and $\Psi$ are plotted $v s$. different angle of incidences. Lines correspond to the simulation of the angular dependence of the parameters. 

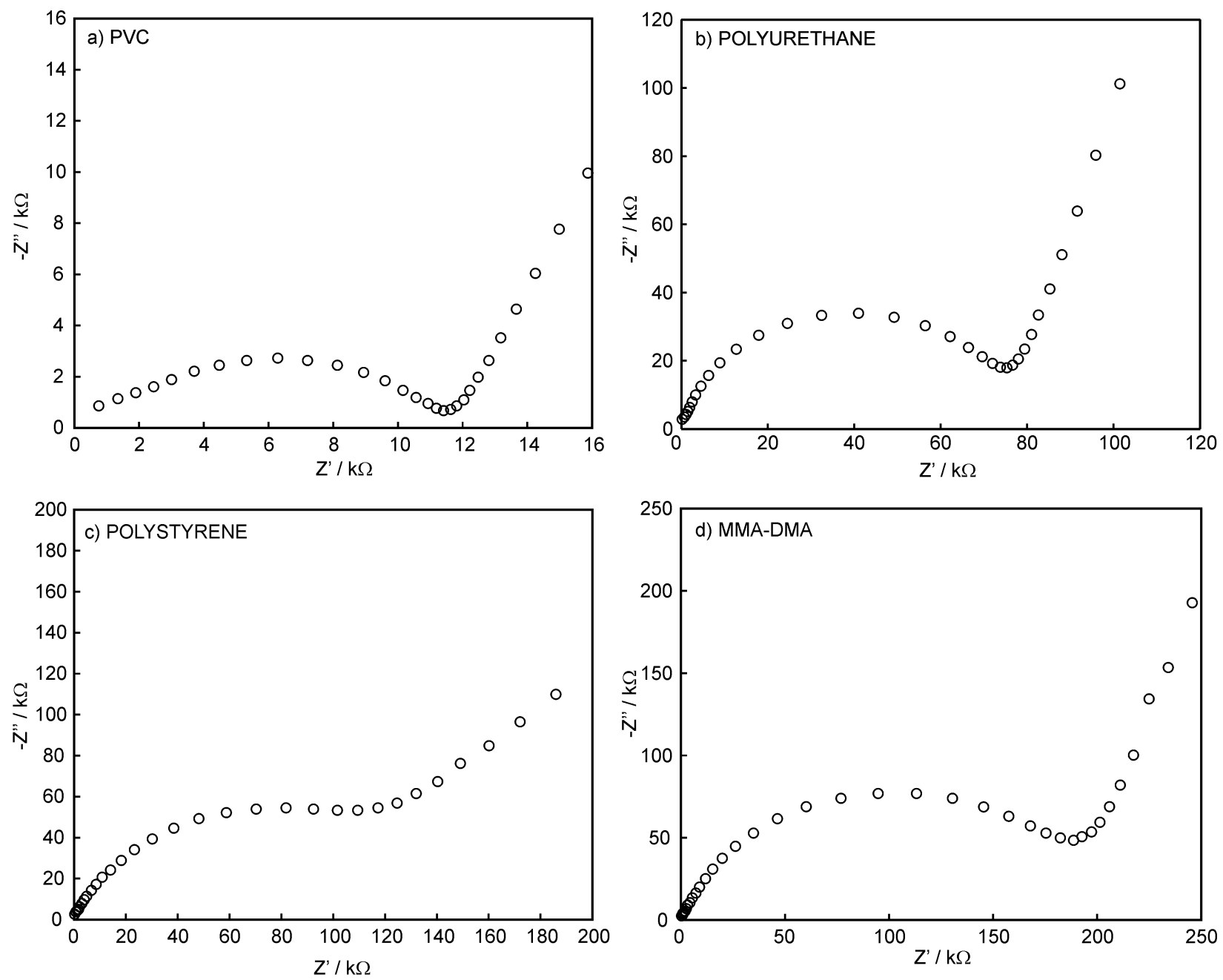

Figure SI-5. Complex impedance plots observed for a) PVC, b) polyurethane c) polystyrene and d) MMA-DMA membranes (MI-IV, see Table SI-1) in $10 \mathrm{mM} \mathrm{NaCl}$ solution. Parameters: first frequency $=100000 \mathrm{~Hz}$, last frequency $=0.1 \mathrm{~Hz}$, number of frequencies $=50$, amplitude $=0.01 \mathrm{~V}$, integration time $=0.125 \mathrm{~s}, \mathrm{Edc}=100 \mathrm{mV}+\mathrm{OCP}(124,201,187$ and $232 \mathrm{mV}$ for PVC, PU, PS and MMA-DMA) 

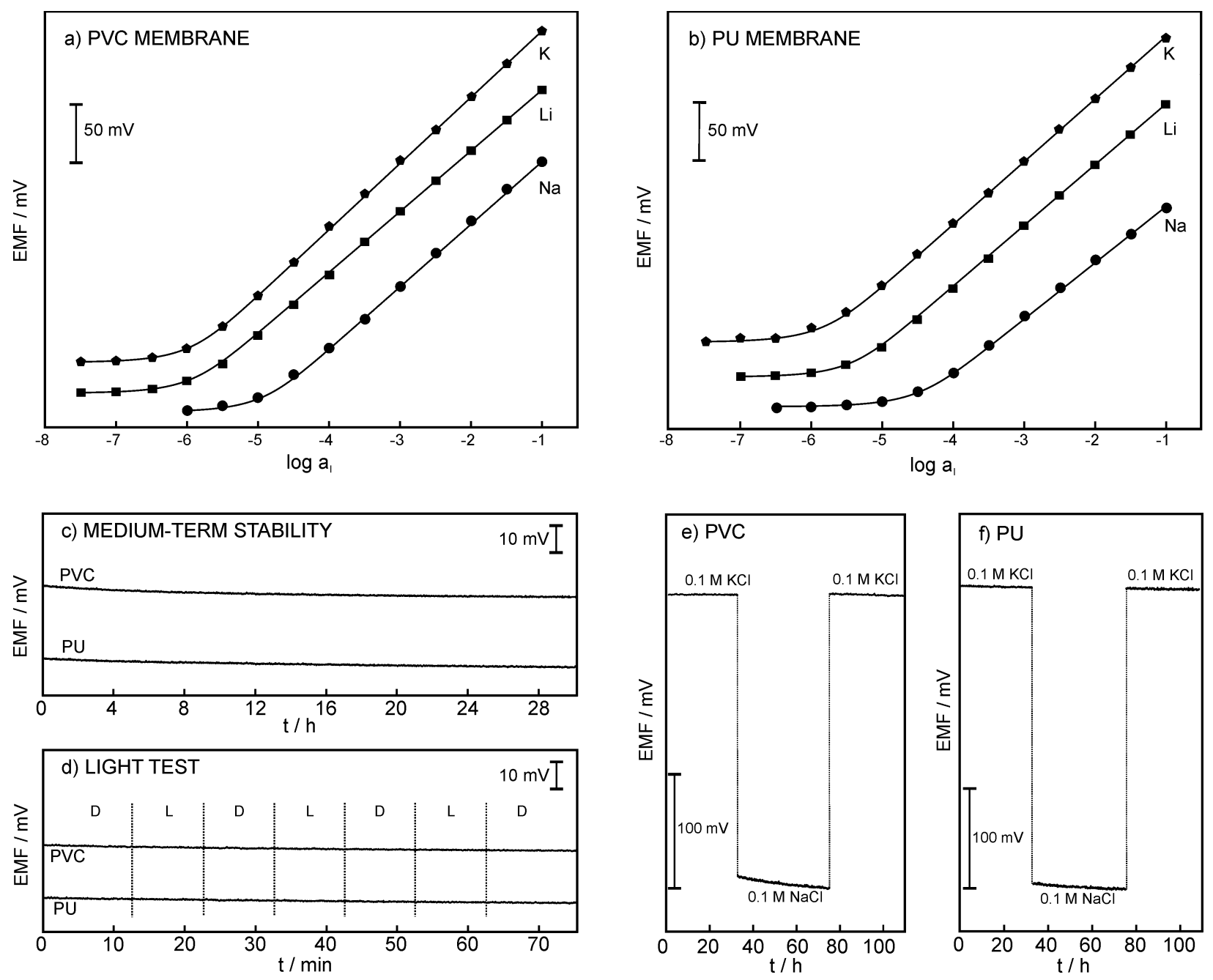

Figure SI-6. a) Potentiometric calibration curves of PVC membranes for sodium (blank membrane, Mi, see Experimental Section, lithium (membrane with Li-I, Mii) and potassium (membrane with K-I, Miii) ( circle $=$ control, square=lithium and triangle=potassium) b) Potentiometric calibration curves of PU membranes for sodium (blank membrane, Miv), lithium (membrane with Li-I, Mv) and potassium (membrane with K-I, Mvi) ( circle=control, square=lithium and triangle=potassium). c) Potentiometric medium-term stability for PVC and PU membranes in a solution of $1 \mathrm{mM} \mathrm{KCl}$ over $28 \mathrm{hs}$. d) Light test in $1 \mathrm{mM} \mathrm{KCl}$ solution using a $60 \mathrm{~W}$ bulb placed at $50 \mathrm{~cm}$ far from the potentiometric cell (L:light on, D:light off). e) Water layer test for PVC membrane. f) Water layer test for PU membrane. A membrane containing K-I was used for the experiments shown in c), d), e) and f). Error bars (n=3) for a) and b) are smaller than the plot markers.

Calculated response times ( $\mathrm{t}_{95}$ ): less than $12 \mathrm{~s}$ and $14 \mathrm{~s}$ for PVC and PU membranes respectively. Acceptable drifts over $28 \mathrm{~h}$ were obtained $\sim 0.15$ and $0.1 \mathrm{mV} \mathrm{h}^{-1}$ for PVC and PU membranes respectively. 


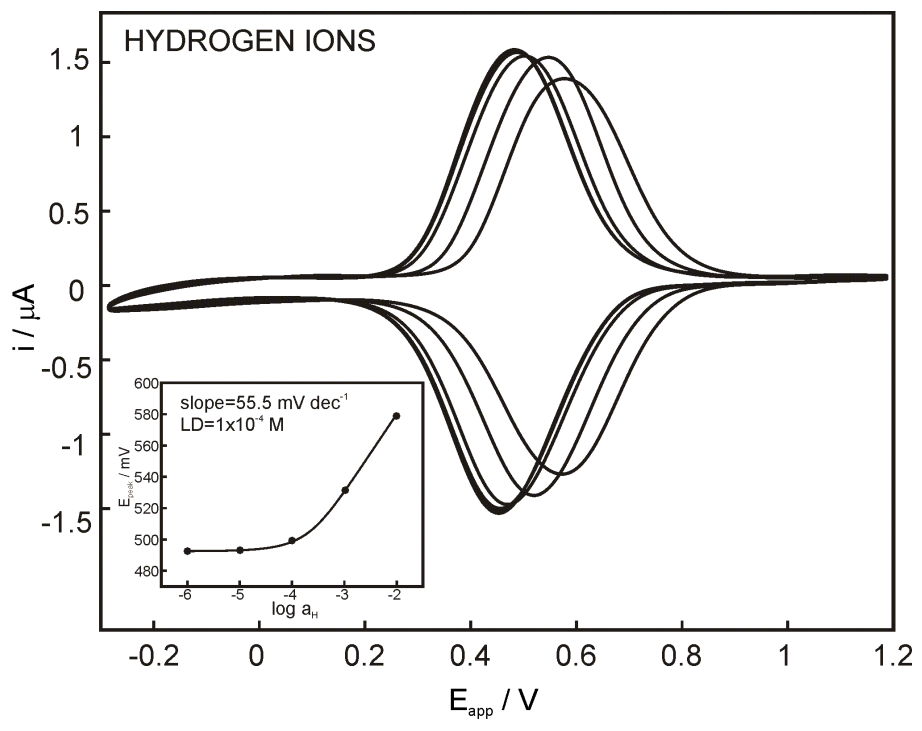

Figure SI-7. Observed cyclic voltammograms for increasing concentrations of $\mathrm{HCl}\left(10^{-6}, 10^{-5}, 10^{-4}, 10^{-3}\right.$ and $10^{-2} \mathrm{M}$ ) using MII in $10 \mathrm{mM} \mathrm{NaCl}$ background solution. Inset: Corresponding calibration curve $\left(\log a_{H C l}\right.$ vs. peak potential). Scan rate: $100 \mathrm{mV} \mathrm{s}^{-1}$. 

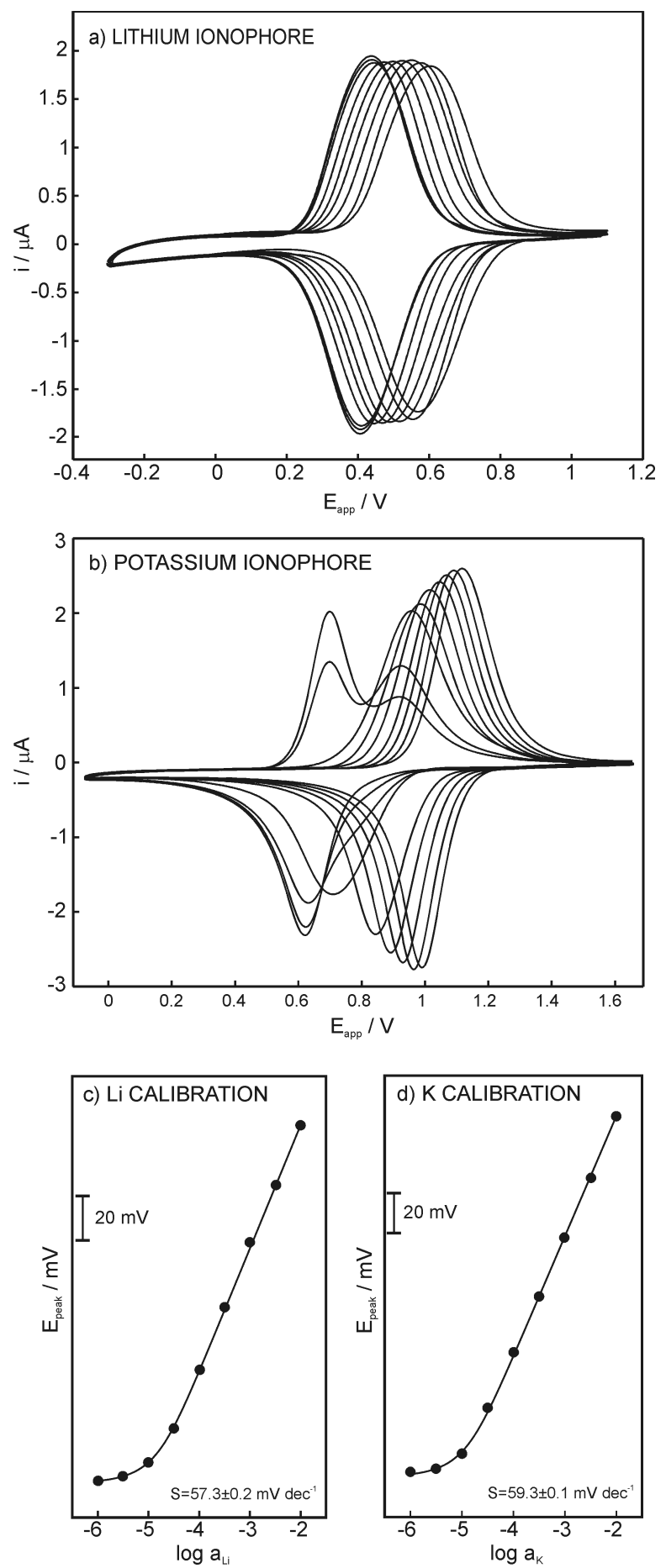

Figure SI-8. (a) Cyclic voltammograms for increasing concentrations of lithium using PU membrane MX (with lithium ionophore) in $10 \mathrm{mM} \mathrm{NaCl}$ background solution. (b) Cyclic voltammograms obtained for increasing concentrations of potassium using PU membrane MXI (with potassium ionophore) in $10 \mathrm{mM}$ $\mathrm{NaCl}$ background solution. (c) Calibration curve for lithium. (d) Calibration graph for potassium. Scan rate $=100 \mathrm{mV} \mathrm{s}^{-1}$. Error bars $(\mathrm{n}=3)$ for $(\mathrm{c})$ and $(\mathrm{d})$ are smaller than the plot markers. Cation concentrations: $1 \times 10^{-6}, 3.16 \times 10^{-6}, 1 \times 10^{-5}, 3.16 \times 10^{-5}, 1 \times 10^{-4}, 3.16 \times 10^{-4}, 1 \times 10^{-3}, 3.16 \times 10^{-3}, 1 \times 10^{-2} \mathrm{M}$. 


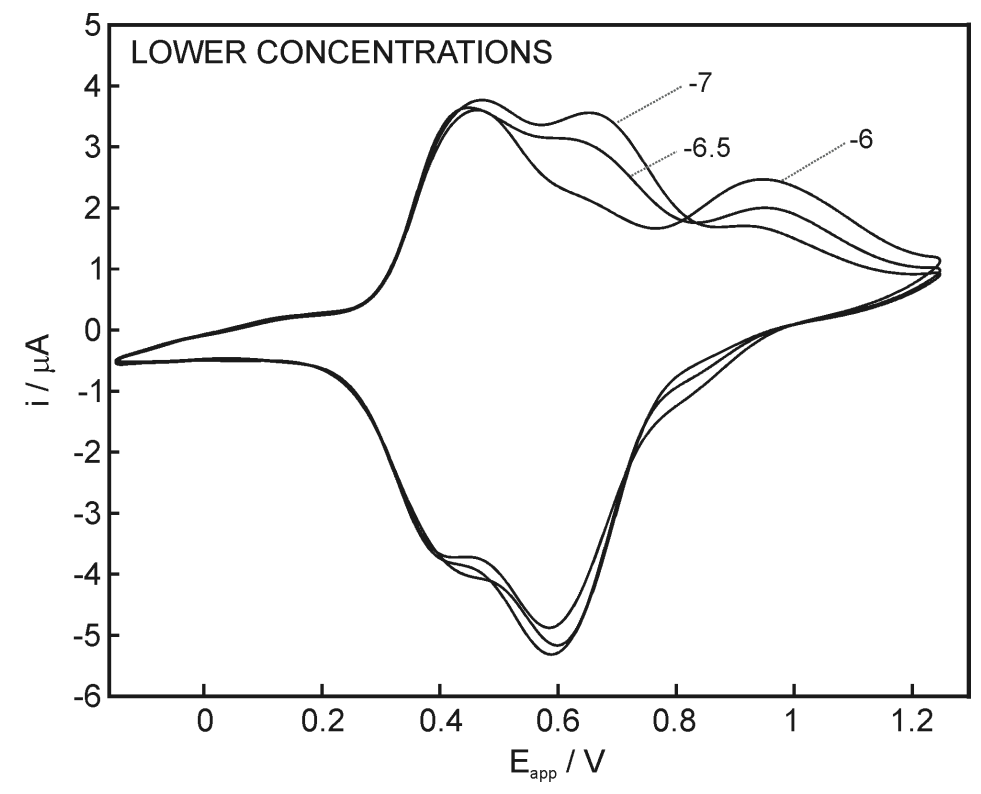

Figure SI-9. Cyclic voltammograms obtained for different equimolar concentrations of lithium and potassium $\left(1 \times 10^{-7}, 3.16 \times 10^{-7}, 1 \times 10^{-6} \mathrm{M}\right)$ using MXIII in $10 \mathrm{mM} \mathrm{NaCl}$ background solution. Scan rate: $100 \mathrm{mV} \mathrm{s}^{-1}$. Logarithmic lithium and potassium activity for each curve is indicated in the figure. 


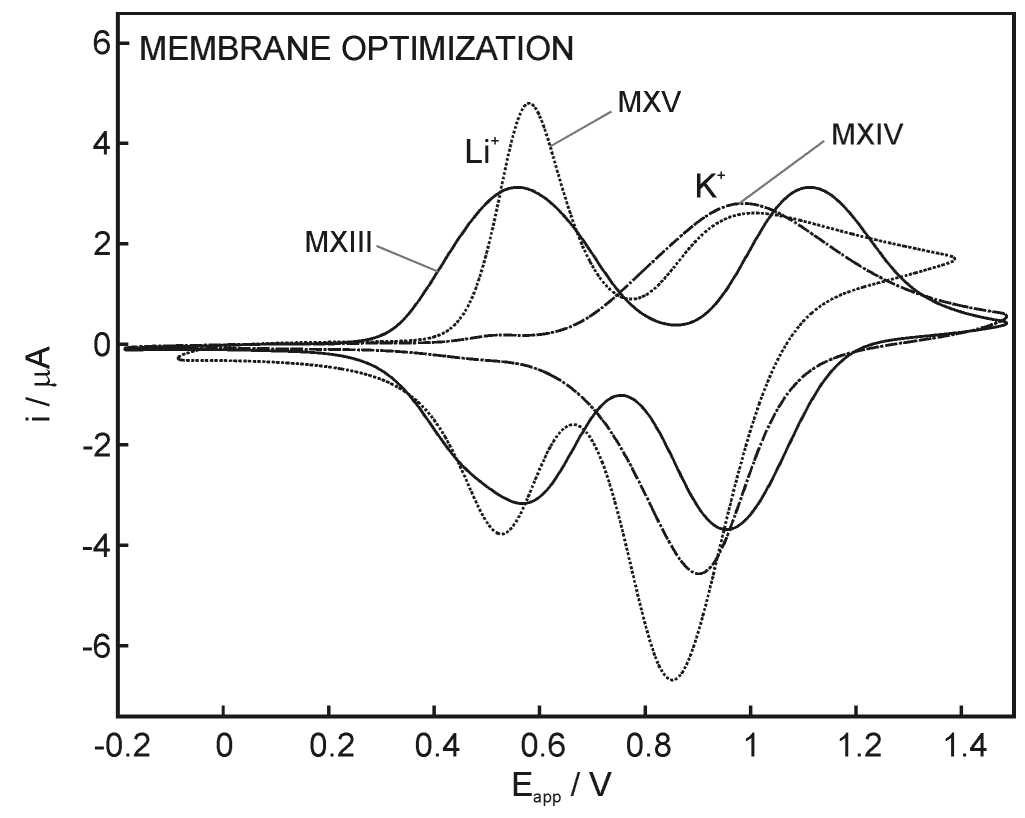

Figure SI-10. Observed cyclic voltammograms for $10 \mathrm{mM} \mathrm{LiCl}$ and $\mathrm{KCl}$ solution $(10 \mathrm{mM} \mathrm{NaCl}$ background electrolyte) using PU membranes containing two ionophores with different compositions (MXIII-XV, Table SI-1). Scan rate: $100 \mathrm{mV} \mathrm{s}^{-1}$.

The membrane containing a lower amount of cation-exchanger (M XIV, Table SI-1) only exhibited the ion transfer wave corresponding to potassium. This was in principle expected since, according to the binding constants, ${ }^{1}$ potassium is preferably extracted in the membrane if the amount of cation-exchanger is not sufficient for the two transfer processes. On the other hand, a higher cation-exchanger concentration (MXV) resulted in a wider asymmetric forward peak for potassium. This behavior was likely due to the formation of complexes with a higher stoichiometry (different from 1:1) caused by an excess of cationexchanger. Amemiya et al. recently proposed that stoichiometry between ionophore-analyte not only modulate the peak current and peak potential, but also the symmetry of the peak shape. ${ }^{7}$ For instance, asymmetric peaks for calcium membranes (1:2 and 1:3 stoichiometry) are expected. 


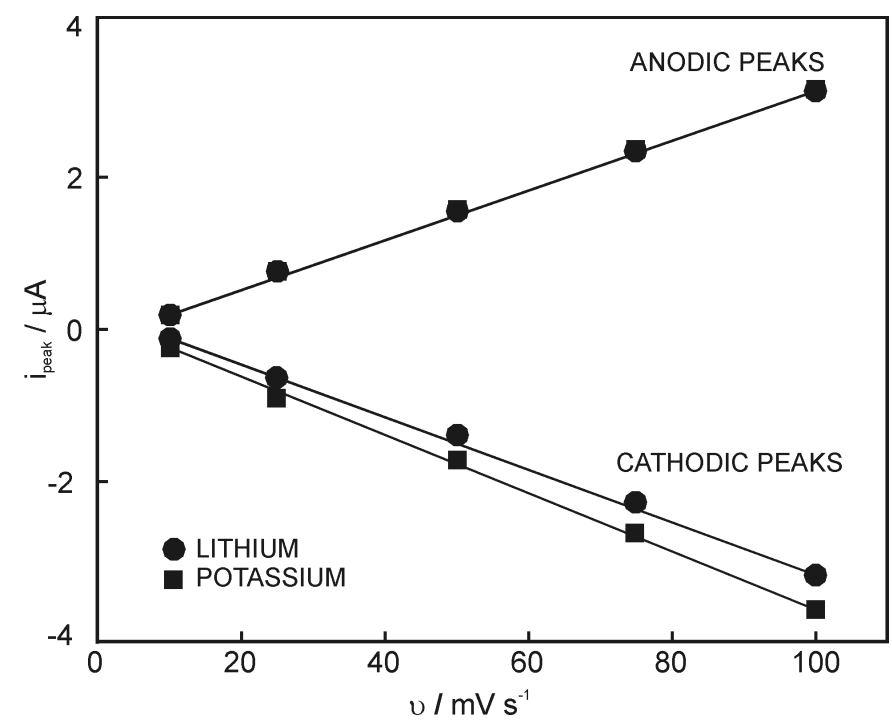

Figure SI-11. Thin layer behavior of membrane XIII containing lithium and potassium ionophores (using cyclic voltammograms shown in Figure 3d). 

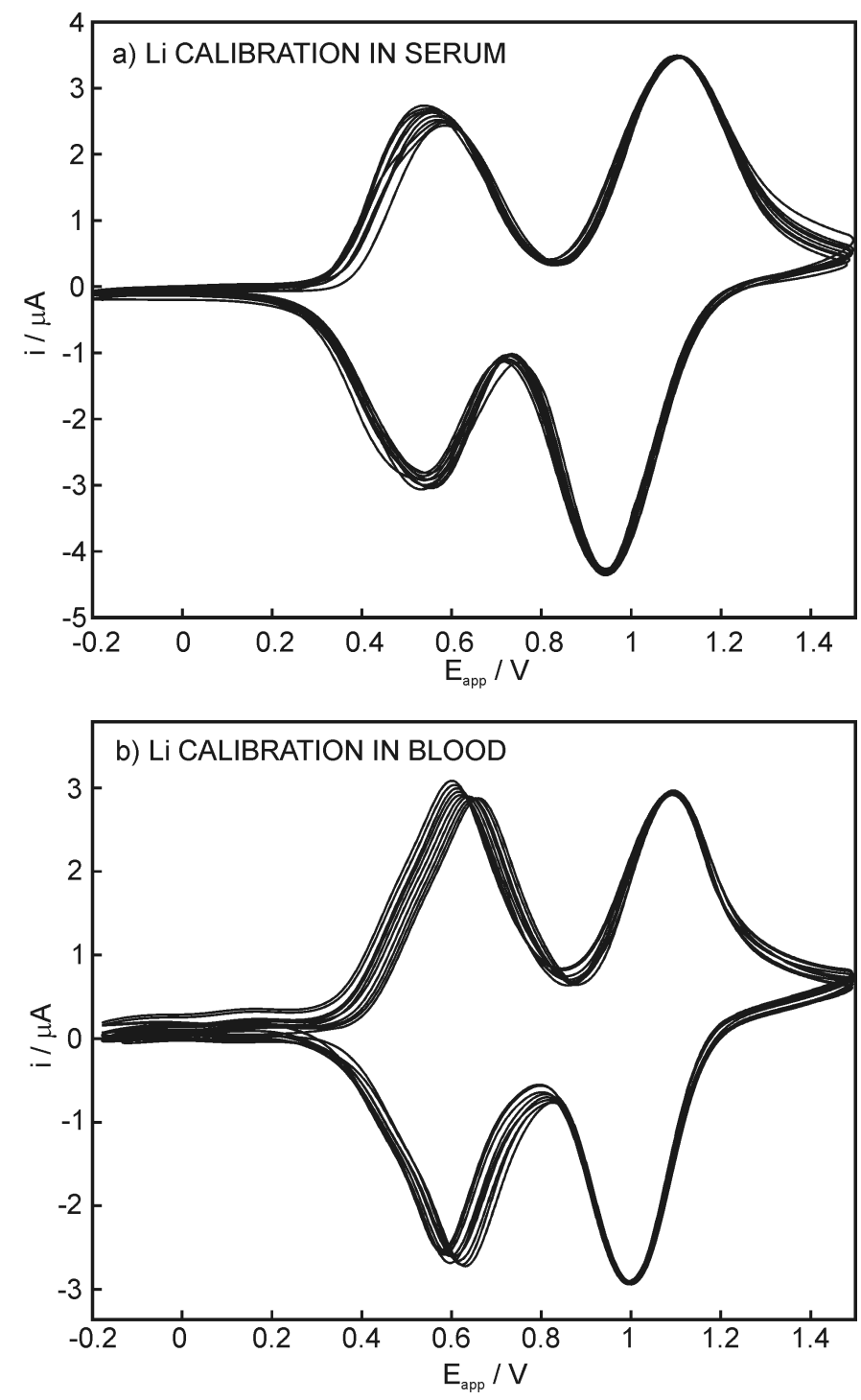

Figure SI-12. Cyclic voltammograms obtained in undiluted serum (a) and blood (b) for increasing lithium activities using MXIII (containing lithium and potassium ionophores). Corresponding calibration graphs for lithium are shown in the main text (Figure 4). Note that the first voltammogram shown corresponds to the unspiked samples. 

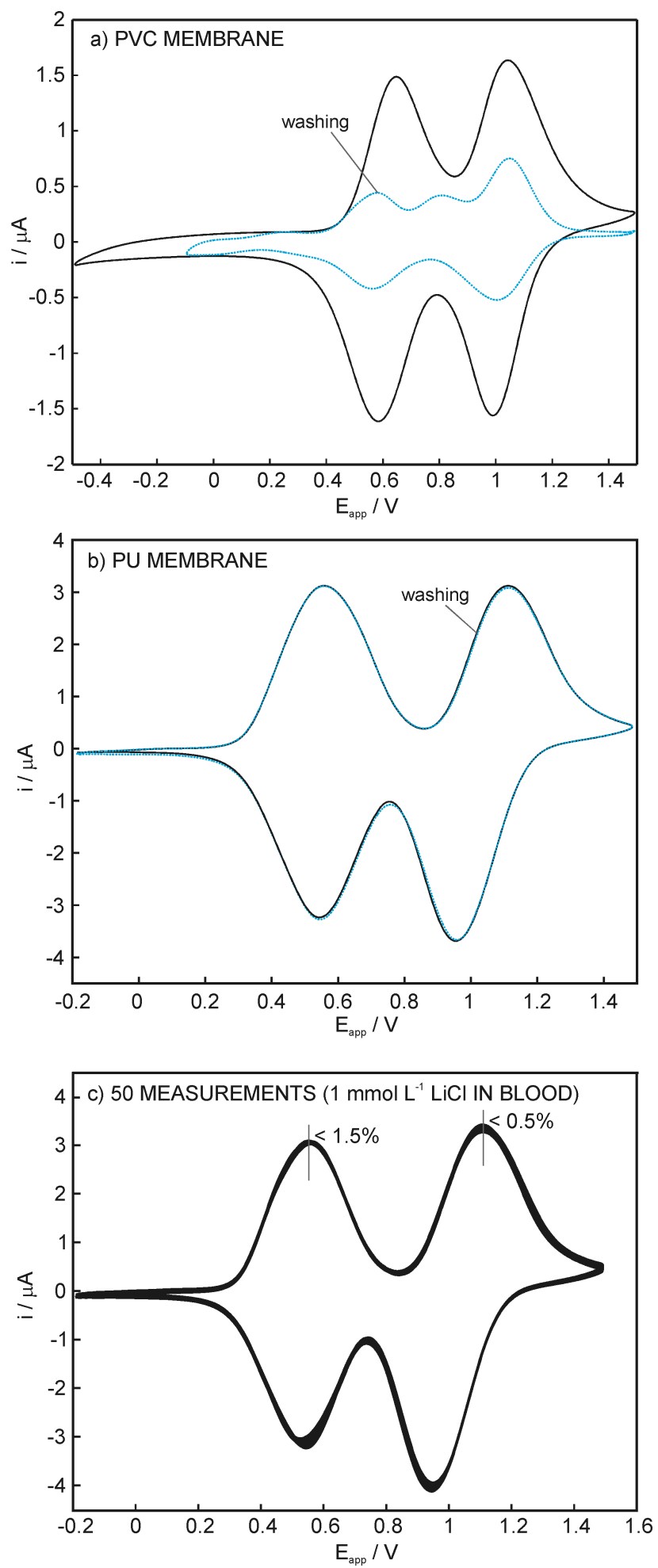

Figure SI-13. Comparison of the cyclic voltammograms obtained for a) PVC (MXII) and b) PU (MXIII) membranes (containing lithium and potassium ionophores) before and after rinsing with water. c) Cyclic voltammograms obtained with the PU membrane (MXIII) in blood containing $1 \mathrm{mmol} \mathrm{L}^{-1}$ lithium after rinsing the membrane 50 times with a direct waterjet. Scan rate: $100 \mathrm{mV} \mathrm{s}^{-1}$. 


\section{References}

1. Qin, Y.; Peper, S.; Bakker, E., Electroanal. 2002, 14, 1375-1381.

2. Rius-Ruiz, F. X.; Bejarano-Nosas, D.; Blondeau, P.; Riu, J.; Rius, F. X., Anal. Chem. 2011, 83, 5783-5788.

3. Yuan, D. J.; Anthis, A. H. C.; Afshar, M. G.; Pankratova, N.; Cuartero, M.; Crespo, G. A.; Bakker, E., Anal. Chem. 2015, 87, 8640-8645.

4. (a) Kepley, L. J.; Bard, A. J., Anal. Chem. 1988, 60, 1459-1467; (b) Ceron Solis, J.; De la Rosa, E.; Pena Cabrera, E., Opt. Mater. 2006, 29, 167-172.

5. Sanchez, I.; Lopez, M. P.; Ortega, J. M.; Climent, M. A., Materials and Corrosion-Werkstoffe Und Korrosion 2011, 62, 139-145.

6. (a) Bobacka, J.; McCarrick, M.; Lewenstam, A.; Ivaska, A., Analyst 1994, 119, 1985-1991; (b) Cosofret, V. V.; Erdosy, M.; Raleigh, J. S.; Johnson, T. A.; Neuman, M. R.; Buck, R. P., Talanta 1996, 43, 143-151.

7. Greenawalt, P. J.; Garada, M. B.; Amemiya, S., Anal. Chem. 2015, 87, 8564-8572. 